\title{
Acta
Biochimica
Polonica
}

Vol. 46 No. $3 / 1999$

$641-650$

QUARTERLY

\section{Conformational analysis of a novel cyclic enkephalin analogue using NMR and EDMC calculations ${ }^{\star \bullet}$}

\author{
Marta Sidor ${ }^{1}$, Jacek Wójcik ${ }^{1 ब s}$, Danuta Pawlak ${ }^{2}$ and Jan Izdebski ${ }^{2 \infty}$ \\ ${ }^{1}$ Laboratory of Biological NMR, Institute of Biochemistry and Biophysics, Polish Academy of \\ Sciences, A. Pawińskiego 5a, 02-106 Warszawa, Poland; \\ ${ }^{2}$ Laboratory of Peptides, Department of Chemistry, University of Warsaw, L. Pasteura 1, \\ 02-093 Warszawa, Poland
}

Received: 23 June, 1999

Key words: cyclic enkephalin, cyclo( $\mathrm{N}^{\ell}, \mathrm{N}^{\varepsilon^{\prime}}$-carbonyl-D-Lys ${ }^{2}$, Lys $\left.{ }^{5}\right)$ enkephalinamide, conformation, BDMC, NMR

Conformational space of a novel cyclic enkephalin analogue, cyclo( $\left(N^{\varepsilon}, N^{\varepsilon^{\prime}}\right.$-car bonyl-D-Lys ${ }^{2}, \mathrm{Lys}^{5}$ )enkephalinamide, was exhaustively examined. A large number of conformations was selected and clustered into families on the basis of their structure and energy. For representative conformations ROESY spectra were generated and their linear combination was fitted to the spectra measured in water and $\mathrm{Me}_{2} \mathrm{SO}_{6}$. This procedure yielded an ensemble of most populated conformations of the peptide in the two solvents.

Based on the enkephalin sequence [Tyr-GlyGly-Phe-(Met) or (Leu)] as a starting point, various opioid peptide analogues have been prepared. Structural modifications are known

\footnotetext{
"Presented at the symposium "Conformation of peptides, proteins and nucleic acids" held in Rynia, Poland, on 26-29 May, 1999.

The use of the NMR facility of the Laboratory of Biological NMR, Institute of Biochemistry and Biophysics, Polish Academy of Sciences (partly supported by the State Committee for Scientific Research, grant E-35/SPUB/P04/206/97) is gratefully acknowledged.

${ }^{\Xi}$ Correspondence to: Jacek Wójcik, tel/fax: (48 22) 658 4683; e-mail: jacekw@ibb.waw.pl; Jan Izdebski, fax: (48 22) 822 5996; e-mail: izdebski@chem.uw.edu.pl

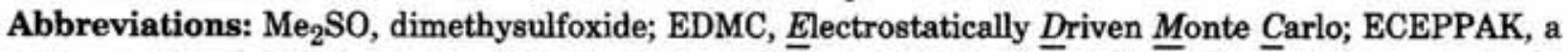
program for global conformational analysis of peptides; ECEPP/3, Empirical $\underline{C}$ nformational Energy Program for Peptides; SRFOPT, a model of fitting to small-molecule free energy hydration with atomic solvation parameters optimized using nonpeptide thermodynamic data; CLUST, a program for cluster analysis; part of ANALYZE; MORASS, $\underline{M}$ ultiple $\underline{O}$ verhauser Relaxation $\underline{A}$ nalysis $\underline{S}$ and $\underline{S}$ imulation; part of ANALYZE; DSS, 2,2-dimethyl-2-silapentate-sulfonic acid; TOSCY, $\underline{T O}$ tal $\underline{\text { Correlated }}$ Spectroscop $\underline{Y}$;

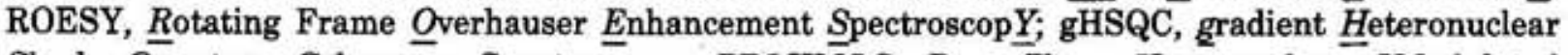
$\underline{S}$ ingle Quantum Coherence Spectroscopy; PPJ-HMQC, $\underline{P} u r e \underline{P}$ hase Homonuclear $\underline{J}$-Modulated

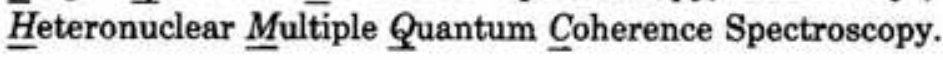


to have great influence on peptide activity and receptor specificity. While natural enkephalins bind preferably to $\delta$-receptor and show somewhat reduced affinity for $\mu$-receptor as compared to morphine, modified peptides express different profiles of interaction with these receptors. Information about a set of conformations, in which the peptides would be more likely to bind to a receptor is of crucial importance for understanding of the receptor-ligand interaction and also would provide a rational basis for designing of new opioid peptides. Since the number of routable bonds in enkephalin and its linear analogue is too large to permit a search of all conformational possibilities, it is necessary to apply various strategies for selecting a limited number of conformations through incorporation of various constraints. The most drastic restriction of the overall conformation has been achieved through cyclization via side chain to side chain or side chain to C-terminal backbone. When the conformationally restricted analogue is active, the number of conformations, which should be taken into account, is greatly reduced. Most of cyclic enkephalin analogues examined so far have been prepared either by disulphide bond formation between apropriately situated half-cystine [1] and penicillamine $[2,3]$ residues, or by amide bond formation between the side-chain amino group of an $\alpha, \omega$-diamino-acid residue and the C-terminal carboxyl group $[4,5]$ or with the side-chain carboxyl group of a glutamic or aspartic acid residue [6]. Recently, we described a novel type of cyclic enkephalin analogue in which the side-chain ring formation was achieved via ureido group incorporating the $\varepsilon$-amino group of the side-chain containing two lysine residues, cyclo $\left(N^{\epsilon}, N^{e^{\prime}}\right.$-carbonylD-Lys ${ }^{2}$, Lys $^{5}$ )enkephalinamide [7]. The opioid activity of the peptide in standard test based on inhibition of electrically evoked contractions of the guinea pig ileum (GPI), mainly mediated by $\mu$-receptors, was about 12 times higher than enkephalin activity. However, in the mouse vas deferens (MVD) test, where predominant receptors are of the $\delta$ type, the peptide was less active than enkephalin. MVD to GPI activity ratio was 3.59 as compared to 0.046 for Leuenkephalin. Conformational analysis of this cyclic enkephalin analogue containing a carbonyl bridge is necessary for rational designing of new peptides with increased activity by modification of this molecule through incorporation of different basic amino acids instead of lysine, as this would result in changes in the ring size.

\section{MATERIALS AND METHODS}

Sample preparation. The cyclic peptide was synthesized by a combination of the solidphase technique and the classical method in solution, and purified by gel filtration followed by reverse phase HPLC as described by Pawlak et al. [7]. To obtain the aqueous solution for NMR measurements the peptide was mixed with a small volume, about $10 \mu \mathrm{L}$, of tetradeuteroacetic acid (min. 99\%, Uvasol) and then dissolved in a mixture of $\mathrm{H}_{2} \mathrm{O}$ (DDI) and $\mathrm{D}_{2} \mathrm{O}$ (99.8\% isotopic purity, Dr. Glaser AG Basel) at 10/1 ratio. The final $\mathrm{pH}$ of the solution was 2.7. After measurements the sample was lyophilized for more than $24 \mathrm{~h}$ to remove traces of acetic acid, and dissolved in $\mathrm{Me}_{2} \mathrm{SO}_{6}$ ( $>99.8 \%$ isotopic purity, Dr. Glaser AG Basel, Switzerland). The peptide concentration of $7.0 \mathrm{mM}$ was applied throughout.

NMR measurements. NMR spectra were measured at ambient temperature on a UNITY500plus (Varian) spectrometer equipped with a gradient generator unit Performa II, WFG, Ultrashims, and high stability temperature unit using $5 \mathrm{~mm}{ }^{1} \mathrm{H}\left({ }^{13} \mathrm{C} /{ }^{15} \mathrm{~N}\right\}$ PFG triple probe. All spectra were measured with water signal presaturation pulse typically of $2 \mathrm{~dB}$ and $1.5 \mathrm{~s} .1 \mathrm{D}$ proton experiments were taken at $2,10,20,30,40$ and $50^{\circ} \mathrm{C}$ in water and at $20,30,40$ and $50^{\circ} \mathrm{C}$ in $\mathrm{Me}_{2} \mathrm{SO}-d_{6} .16 \mathrm{k}$ points were collected and spectral width of $6 \mathrm{kHz}$ was used. $2 \mathrm{D}$ experiments were performed using proton spectral width of $4.5 \mathrm{kHz}$ collecting $2 \mathrm{k}$ 
points. TOCSY [8-10] and ROESY $[11,12]$ experiments were measured at 2,20 and $35^{\circ} \mathrm{C}$ for aqueous solution and at $20^{\circ} \mathrm{C}$ in $\mathrm{Me}_{2} \mathrm{SO}_{-} \mathrm{d}_{6}$ with 256 increments. Mixing time of $0.2 \mathrm{~s}$ was used in TOCSY for either solvent while 0.2 and $0.4 \mathrm{~s}$ for aqueous and $0.1,0.2,0.3,0.4 \mathrm{~s}$ for $\mathrm{Me}_{2} \mathrm{SO}_{-} d_{6}$ solution in ROESY measurements. The $\left\{{ }^{1} \mathrm{H} /{ }^{13} \mathrm{C}\right\}$ gHSQC [13-15] experiment with gradients was performed in the proton decoupled mode at $20^{\circ} \mathrm{C}$, carbon spectral width $25 \mathrm{k}$ and 256 increments for either solvent. The $\left\{{ }^{1} \mathrm{H} /{ }^{15} \mathrm{~N}\right\} \mathrm{gHSQC}$ experiment with gradients was performed in the proton decoupled mode at $20^{\circ} \mathrm{C}$ with nitrogen spectral width $2 \mathrm{kHz}$ and 128 increments. The PPJ-HMQC [16] experiment in the proton decoupled mode with nitrogen spectral width 1.5 $\mathrm{kHz}$ and 64 increments was performed in aqueous solution at $20^{\circ} \mathrm{C}$.

Spectra calibration. All proton spectra in aqueous solution were calibrated against water signal using the equation $\delta_{1 \mathrm{H}}(t)=5.060$ $0.0122 \cdot t+\left(2.11 \times 10^{-5}\right) \cdot t^{2}[17]$ where $t$ is given in ${ }^{\circ} \mathrm{C}$. External reference signals were used for calibration of correlation spectra DSS [18] for carbon axis in $\left\{{ }^{1} \mathrm{H} /{ }^{13} \mathrm{C}\right\}$ spectra and $\mathrm{NH}_{3}$ signal [18] for nitrogen axis in $\left\{{ }^{1} \mathrm{H} /{ }^{15} \mathrm{~N}\right\}$ spectra. In $\mathrm{Me}_{2} \mathrm{SO}-d_{6}$ solution the residual solvent signal was used as a reference [19] in both, proton and carbon dimensions, utilizing equations $\delta_{1 \mathrm{H}}(T)=2.6725-0.000795$. $T+0.000000742 \cdot T^{2}$, and $\delta_{13 c}(T)=36.8269+$ $0.008792 \cdot T$, where $T$ was expressed in $\mathrm{K}$.

Calculation method. In our study we explored the conformational space of cyclo$\left(N^{\ell}, N^{\epsilon^{\prime}}\right.$-carbonyl-D-Lys ${ }^{2}$,Lys ${ }^{5}$ )enkephalinamide using the method proposed by Liwo et al. [20] that included the Electrostatically Driven Monte Carlo, EDMC method [21, 22]. In our calculations we have used the ECEPPAK program that started with a conformation of random geometry whose energy was minimized with the ECEPP/3 force field [23] and surface model SRFOPT [24]. In this model in addition to a sum of electrostatic, non-bonding, hydrogen-bond and torsional energy terms, the total conformational energy includes terms ac- counting for loop closing and peptide solvatation. The conformation with minimized energy was subsequently perturbed by changing its torsional $\psi$ and $\varphi$ angles using the Monte Carlo method [25]. Piela's algorithm [26], which was also applied at this stage, greatly improves the acceptance coefficient. In this algorithm $\psi$ and $\varphi$ angles are changed in a manner which allows the corresponding peptide group to find the most proper orientation in the electrostatic field of the rest of the peptide chain. The energy of the new conformation is minimized, compared to the previous one and can be accepted or discarded on the basis of energy and/or geometry. If the conformation is accepted the procedure is repeated. A temperature jump may be included if the perturbation is not successful for an arbitrarily chosen number of iterations. The full pathway of conformation generation is sketched in Scheme 1.

The ensemble of obtained conformations was then clustered into families using the program CLUST [28], which applies the minimum-variance procedure for separation. This procedure allows for substantial reduction of the number of conformations and eliminates repetitions. In our case a total of 13937 conformations were generated using 988 electrostatically predicted perturbations and 12649 random perturbations; 3000 conformations were accepted. They were clustered into 870 families using energy treshold of $20 \mathrm{kcal} / \mathrm{mol}$ and rmsd of $0.15 \AA$ as separation criteria. The available version of the ECEPPAK program contains solvent parameters for peptide-water interactions only. Therefore families of conformations generated with parameters accounting for peptide-water interactions were used in the subsequent comparison with the experimental data obtained for peptide solution in water and in $\mathrm{Me}_{2} \mathrm{SO}_{-} d_{6}$ as well.

For estimation of population of particular conformations, families of the NOESY spectra were generated for representatives of each family with the program MORASS [29, 30]. A linear combination of the generated spectra 


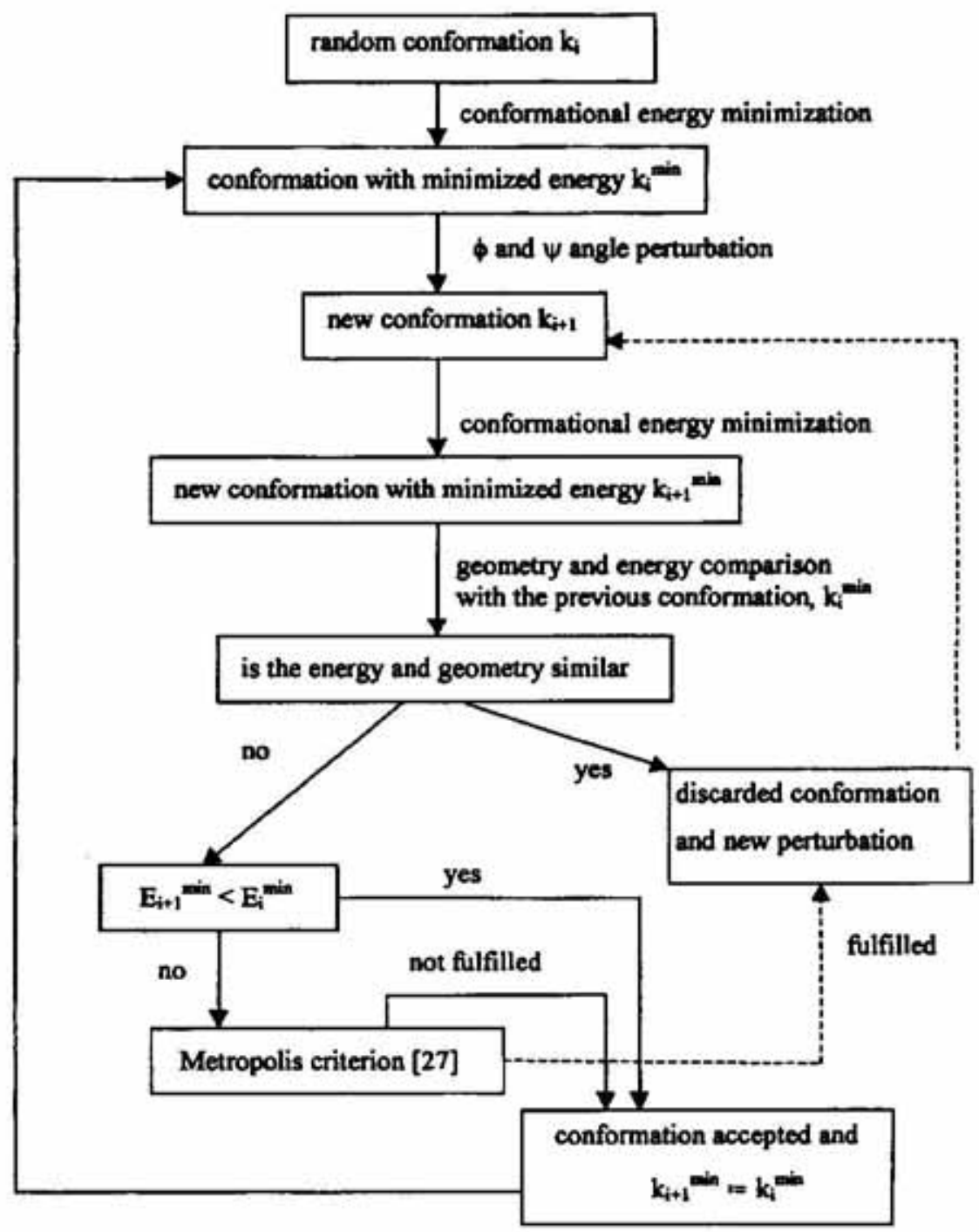

Scheme 1. Pathway of generation of the enkephalin analogue studied conformations.

For details see text.

was fitted to the experimental spectrum using the Marquardt method [31]. A separate term with additional statistical weight was introduced to account for couplings. In this way the statistical weights for each of the conformational families was found.

For either solvent and all conformations the NOESY spectra were generated using correlation time of $0.45 \mathrm{~ns}$ and mixing time of $0.2 \mathrm{~s}$. In fitting the generated spectra to the experimental ones it was assumed that protons do not yield any cross-peak at distances larger than $6 \AA$, and signals arising from geminal protons were rejected. The statistical weight for the coupling term was set to 0.01 , and the Marquardt convergence criterion value of $10^{-5}$ was used.

\section{RESULTS}

Chemical shifts were assigned to protons on the basis of $1 \mathrm{D}$ and $2 \mathrm{D}$ spectra. Due to the fast exchange the tyrosine $\mathrm{OH}$ and $\mathrm{NH}_{2}$ protons could not be observed in water. Spectra measured in $\mathrm{Me}_{2} \mathrm{SO}_{6}$ show the signals of the $\mathrm{NH}$ protons from the ureido bridge and the $\mathrm{OH}$ signal of tyrosine. The dispersion of the sig- 
nals in the spectra measured in $\mathrm{Me}_{2} \mathrm{SO}_{-} d_{6}$ is much better than that in the spectra measured in the aqueous solution.

The analysis of TOCSY and ROESY spectra confirmed the composition and sequence of the novel enkephalin analogue. Full signal assignment was possible with the use of heteronuclear $\left\{{ }^{1} \mathrm{H} /{ }^{13} \mathrm{C}\right\} \mathrm{HHSQC}$ correlation spectra. It also appeared necessary to measure $\left\{{ }^{1} \mathrm{H} /{ }^{15} \mathrm{~N}\right\} \mathrm{gHSQ}$ spectra in order to properly assign amide protons. All 37 and 48 signals in water and $\mathrm{Me}_{2} \mathrm{SO}-d_{6}$, respectively, have been assigned. The ROESY spectrum used for the structure calculation was measured using the $0.2 \mathrm{~s}$ mixing time. ROE signal intensities were recalculated to NOE ones according to the equation given by Croasmun \& Carlson [32]. The spectrum was analyzed using VNMR 5.1A (Varian) software. A total of 73 and 93 (in water and $\mathrm{Me}_{2} \mathrm{SO}_{-} d_{6}$, respectively) well separated off-diagonal cross-peaks were integrated and used in the structure calculation. Among them 32 and 34, respectively, were inter-residual peaks.

Vicinal couplings within the peptide in water were measured using the PPJ-HMQC heteronuclear technique because of strong overlapping of signals. The measured chemical shifts and couplings are given in Table 1.

Table 1. Chemical shifts and vicinal couplings measured for cyclo( $\left(N^{\varepsilon}, N^{\varepsilon}\right.$-carbonyl-D-Lys $\left.{ }^{2}, \mathrm{Lys}^{5}\right)$ enkephalinamide at $20^{\circ} \mathrm{C}$ in $\mathrm{H}_{2} \mathrm{O}$ and in $\mathrm{Me}_{2} \mathrm{SO}_{-} d_{6}$

\begin{tabular}{|c|c|c|c|c|c|c|}
\hline Residue & Solvent & NH [ppm] & $\begin{array}{l}{ }^{3} \mathrm{~J}_{\mathrm{Ng}} \\
{[\mathrm{Hz}]}\end{array}$ & $\begin{array}{l}\mathrm{H}_{\alpha} \\
\text { [ppm] }\end{array}$ & $\begin{array}{l}\mathrm{H}_{\beta 1}, \mathrm{H}_{\beta 2} \\
{[\mathrm{ppm}]}\end{array}$ & Other [ppm] \\
\hline \multirow[t]{2}{*}{$\mathrm{Tyr}^{1}$} & $\mathrm{H}_{2} \mathrm{O}$ & - & - & 4.15 & $\begin{array}{l}3.19 \\
2.95\end{array}$ & $7.11\left(\mathrm{H}_{2,6}\right) ; 6.86\left(\mathrm{H}_{3,5}\right)$ \\
\hline & $\mathrm{Me}_{2} \mathrm{SO}$ & - & - & 3.78 & $\begin{array}{l}2.81 \\
2.67\end{array}$ & $6.98\left(\mathrm{H}_{2,6}\right) ; 6.66\left(\mathrm{H}_{3,5}\right) ; 9.27(\mathrm{OH})$ \\
\hline \multirow[t]{2}{*}{ D-Lys ${ }^{2}$} & $\mathrm{H}_{2} \mathrm{O}$ & $\begin{array}{l}8.3 \\
\{-7.3 \pm 0.4\}\end{array}$ & 6.7 & 4.08 & $\begin{array}{l}1.42 \\
1.42\end{array}$ & $\begin{array}{l}0.93\left(\mathrm{H}_{\gamma 1} ; \mathrm{H}_{\gamma 2}\right) ; 1.36\left(\mathrm{H}_{\delta 1}, \mathrm{H}_{\delta 2}\right) \\
3.03\left(\mathrm{H}_{\varepsilon 1} ; 3.09\left(\mathrm{H}_{\varepsilon 2}\right)\right.\end{array}$ \\
\hline & $\mathrm{Me}_{2} \mathrm{SO}$ & $\begin{array}{l}8.2 \\
\{-4.0 \pm 0.0\}\end{array}$ & 6.2 & 4.24 & $\begin{array}{l}1.42 \\
1.42\end{array}$ & $\begin{array}{l}1.08\left(\mathrm{H}_{\gamma 1} ; \mathrm{H}_{\gamma 2}\right) ; 1.26\left(\mathrm{H}_{\delta 1} ; \mathrm{H}_{\delta 2}\right) \\
3.06\left(\mathrm{H}_{\varepsilon 1}\right) ; 2.82\left(\mathrm{H}_{\varepsilon 2}\right) \\
5.66\left(\mathrm{H}_{\mathrm{Ne}}\right) ;\{-2.0 \pm 0.1\}\end{array}$ \\
\hline \multirow[t]{2}{*}{$\mathrm{Gly}^{3}$} & $\mathrm{H}_{2} \mathrm{O}$ & $\begin{array}{l}8.3 \\
\{-6.4 \pm 0.2\}\end{array}$ & - & $\begin{array}{l}3.99 \\
3.74\end{array}$ & & \\
\hline & $\mathrm{Me}_{2} \mathrm{SO}$ & $\begin{array}{l}8.3 \\
\{-4.6 \pm 0.1\}\end{array}$ & $\begin{array}{l}3.4 ; \\
6.9\end{array}$ & $\begin{array}{l}4.08 \\
3.38\end{array}$ & & \\
\hline \multirow[t]{2}{*}{$\mathrm{Phe}^{4}$} & $\mathrm{H}_{2} \mathrm{O}$ & $\begin{array}{l}8.3 \\
\{-9.4 \pm 0.3\}\end{array}$ & 3.7 & 4.54 & $\begin{array}{l}3.05 \\
3.02\end{array}$ & $7.35\left(\mathrm{H}_{2,6}\right) ; 7.26\left(\mathrm{H}_{3,5}\right) ; 7.29\left(\mathrm{H}_{4}\right)$ \\
\hline & $\mathrm{Me}_{2} \mathrm{SO}$ & $\begin{array}{l}8.4 \\
\{-6.3 \pm 0.2\}\end{array}$ & 8.2 & 4.59 & $\begin{array}{l}3.04 \\
2.75\end{array}$ & $7.34\left(\mathrm{H}_{2,6}\right) ; 7.29\left(\mathrm{H}_{3,5}\right) ; 7.19\left(\mathrm{H}_{4}\right)$ \\
\hline \multirow[t]{2}{*}{ Lys $^{5}$} & $\mathrm{H}_{2} \mathrm{O}$ & $\begin{array}{l}8.3 \\
\{-7.9 \pm 0.4\}\end{array}$ & 8.0 & 4.16 & $\begin{array}{l}1.72 ; \\
1.59\end{array}$ & $\begin{array}{l}1.35\left(\mathrm{H}_{\gamma 1}\right) ; 1.26\left(\mathrm{H}_{\gamma 2}\right) ; 1.44\left(\mathrm{H}_{\delta 1}\right) ; \\
1.36\left(\mathrm{H}_{\delta 2}\right) ; 3.05\left(\mathrm{H}_{\varepsilon 1} ; \mathrm{H}_{\varepsilon 2}\right) ; \\
6.91\left(\mathrm{NH}^{\prime} \text { Cend }\{\{-6.0 \pm 0.1\} ;\right. \\
6.59\left(\mathrm{NH}^{\prime \prime} \text { Cend } ; \text { (ca. } 2.4\right\}\end{array}$ \\
\hline & $\mathrm{Me}_{2} \mathrm{SO}$ & $\begin{array}{l}8.2 \\
\{-6.6 \pm 0.1\}\end{array}$ & 8.8 & 4.20 & $\begin{array}{l}1.69 \\
1.50\end{array}$ & $\begin{array}{l}1.28\left(\mathrm{H}_{\gamma 1} ; \mathrm{H}_{\gamma 2}\right) ; 1.32\left(\mathrm{H}_{\delta 1} ; \mathrm{H}_{\delta 2}\right) ; \\
2.94\left(\mathrm{H}_{\varepsilon 1} ; \mathrm{H}_{\varepsilon 2}\right) ; \\
5.48\left(\mathrm{H}_{\mathrm{Nk}^{\prime}}\right) ;\{-1.6 \pm 0.1) ; \\
7.00\left(\mathrm{NH}^{\prime}{ }_{\text {cend }}\right) ;(-4.9 \pm 0.3\} ; \\
7.21\left(\mathrm{NH}^{\prime \prime} \text { Cend }\right) ;(-6.0 \pm 0.1\}\end{array}$ \\
\hline
\end{tabular}

Temperature coefficients $[\mathrm{ppb} / \mathrm{K}]$ for exchangable protons are given in brace parenthesis. 
Table 2. The most populated ten conformations for cyclo $\left(N^{\varepsilon}, N^{\varepsilon^{*}}\right.$-carbonyl-D-Lys ${ }^{2}$, Lys $\left.{ }^{5}\right)$ enkephalinamide in water and $\mathrm{Me}_{2} \mathrm{SO}_{6}$.

$\varphi$ and $\psi$ angles for L-residues are expressed using Zimmerman's code [34] ${ }^{\mathrm{A}}$.

\begin{tabular}{lccccc}
\hline \multirow{2}{*}{ No. } & \multirow{2}{*}{ Relative population (\%) } & \multicolumn{4}{c}{$\mathrm{H}_{2} \mathrm{O}$} \\
\cline { 3 - 6 } & & $\mathrm{Tyr}^{1}$ & $\mathrm{Gly}^{3}$ & $\mathrm{Phe}^{4}$ & $\mathrm{Lys}^{5}$ \\
\hline I & 17.30 & $\mathrm{E}$ & $\mathrm{G}^{*}$ & $\mathrm{~A}$ & $\mathrm{C}$ \\
II & 16.03 & F & $\mathrm{G}^{*}$ & $\mathrm{~B}$ & $\mathrm{~A}$ \\
III & 10.68 & $\mathrm{G}$ & $\mathrm{E}^{*}$ & $\mathrm{E}$ & $\mathrm{F}$ \\
IV & 9.73 & $\mathrm{~F}$ & $\mathrm{D}$ & $\mathrm{D}$ & $\mathrm{F}$ \\
V & 9.68 & $\mathrm{~F}$ & $\mathrm{E}^{*}$ & $\mathrm{E}$ & $\mathrm{E}$ \\
VI & 7.84 & $\mathrm{~B}$ & $\mathrm{D}^{*}$ & $\mathrm{~A}$ & F \\
VII & 5.33 & $\mathrm{G}$ & $\mathrm{G}$ & $\mathrm{C}$ & $\mathrm{A}$ \\
VIII & 4.89 & $\mathrm{~A}$ & $\mathrm{E}^{*}$ & $\mathrm{~B}$ & $\mathrm{~A}$ \\
IX & 4.24 & $\mathrm{~A}$ & $\mathrm{~A}^{*}$ & $\mathrm{G}$ & F \\
X & 3.30 & $\mathrm{~B}$ & $\mathrm{G}$ & $\mathrm{F}$ & $\mathrm{E}$ \\
& & & & &
\end{tabular}

\begin{tabular}{lccccc}
\hline \multirow{2}{*}{ No. } & Relative population & \multicolumn{5}{c}{$\mathrm{Me}_{2} \mathrm{SO}_{6}$} \\
\cline { 3 - 6 } & $(\%)$ & $\mathrm{Tyr}^{1}$ & $\mathrm{Gly}^{3}$ & $\mathrm{Phe}^{4}$ & $\mathrm{Lys}^{5}$ \\
\hline I & 16.28 & $\mathrm{E}$ & $\mathrm{E}^{*}$ & $\mathrm{E}$ & $\mathrm{E}$ \\
II & 15.01 & $\mathrm{~B}$ & $\mathrm{H}^{*}$ & $\mathrm{~F}$ & $\mathrm{~F}$ \\
III & 13.50 & $\mathrm{D}$ & $\mathrm{H}$ & $\mathrm{B}$ & $\mathrm{A}$ \\
IV & 8.71 & $\mathrm{E}$ & $\mathrm{D}$ & $\mathrm{A}$ & $\mathrm{A}$ \\
V & 7.19 & $\mathrm{~F}$ & $\mathrm{D}$ & $\mathrm{A}$ & $\mathrm{C}$ \\
VI & 6.80 & $\mathrm{~F}$ & $\mathrm{D}$ & $\mathrm{B}$ & $\mathrm{A}$ \\
VII & 6.33 & $\mathrm{~F}$ & $\mathrm{G}^{*}$ & $\mathrm{~B}$ & $\mathrm{~F}$ \\
VIII & 6.18 & $\mathrm{G}$ & $\mathrm{G}^{*}$ & $\mathrm{H}$ & $\mathrm{G}$ \\
IX & 5.11 & $\mathrm{~F}$ & $\mathrm{D}$ & $\mathrm{A}$ & $\mathrm{A}$ \\
X & 3.12 & $\mathrm{~F}$ & $\mathrm{E}^{*}$ & $\mathrm{E}$ & $\mathrm{E}$ \\
\hline
\end{tabular}

"A: $\varphi\langle-110,-40\rangle, \psi\langle-90,-10\rangle$; B: $\varphi\langle-180,-110\rangle, \psi\langle-40,-20\rangle \& \varphi\langle-110,-40\rangle, \psi\langle 10,50\rangle$; $: \varphi\langle-110,-40\rangle$, $\psi\langle 50,130\rangle ; \mathrm{D}: \varphi\langle-180,-110\rangle, \psi\langle 20,110\rangle ; \mathrm{E}: \varphi\langle-180,-110\rangle, \psi\langle 110,180\rangle ; \mathrm{F}: \varphi\langle-110,-40\rangle, \psi\langle 130,180\rangle$; G: $\varphi\langle 180,-110\rangle, \psi\langle-90,-40\rangle ; \mathrm{H}: \varphi\langle-40,0\rangle, \psi\langle-180,180\rangle \& \varphi\langle-180,-40\rangle, \psi\langle-140,-90\rangle ; \mathrm{A}^{*}: \varphi\langle 40,110\rangle$, $\psi\langle 10,90\rangle ; \mathrm{D}^{*}: \varphi\langle 110,180\rangle, \psi\langle-110,-20\rangle ; \mathrm{E}^{*}: \varphi\langle 110,180\rangle, \psi\langle-180,-110\rangle ; \mathrm{G}^{*}: \varphi\langle 110,180\rangle, \psi\langle 40,90\rangle ;$ $H^{*}: \varphi\langle 0,40\rangle, \psi\langle-180,180\rangle \& \varphi\langle 40,180\rangle, \psi\langle 90,140\rangle$.

Temperature dependence of amide proton signals

Temperature coefficients of signals of amide and ureido bridge protons are given in Table 1 . It is well known that a temperature coefficient value higher than $-3 \mathrm{ppb} / \mathrm{deg}$ indicates that the proton is involved in an intra-molecular hydrogen bond or that it is well separated from interaction with the solvent [33]. The temperature coefficients measured for the exchangeable protons in the peptide are below this value; however, coefficient values for the amide protons of D-Lys ${ }^{2}$ and $\mathrm{Gly}^{3}$ are very close to it (as one can see from the data in Table 1). This could be due to the presence of some populations of conformations with hydrogen bonds.

\section{Results of calculations}

The applied calculation procedure yielded for each solvent 10 conformations with relative population higher than $3 \%$ (Table 2 ). They sum up to $88 \%$ and $89 \%$ for water and $\mathrm{Me}_{2} \mathrm{SO}_{6}$, respectively.

The $\varphi$ and $\psi$ angles for the L-residues in the most populated conformations are given in 


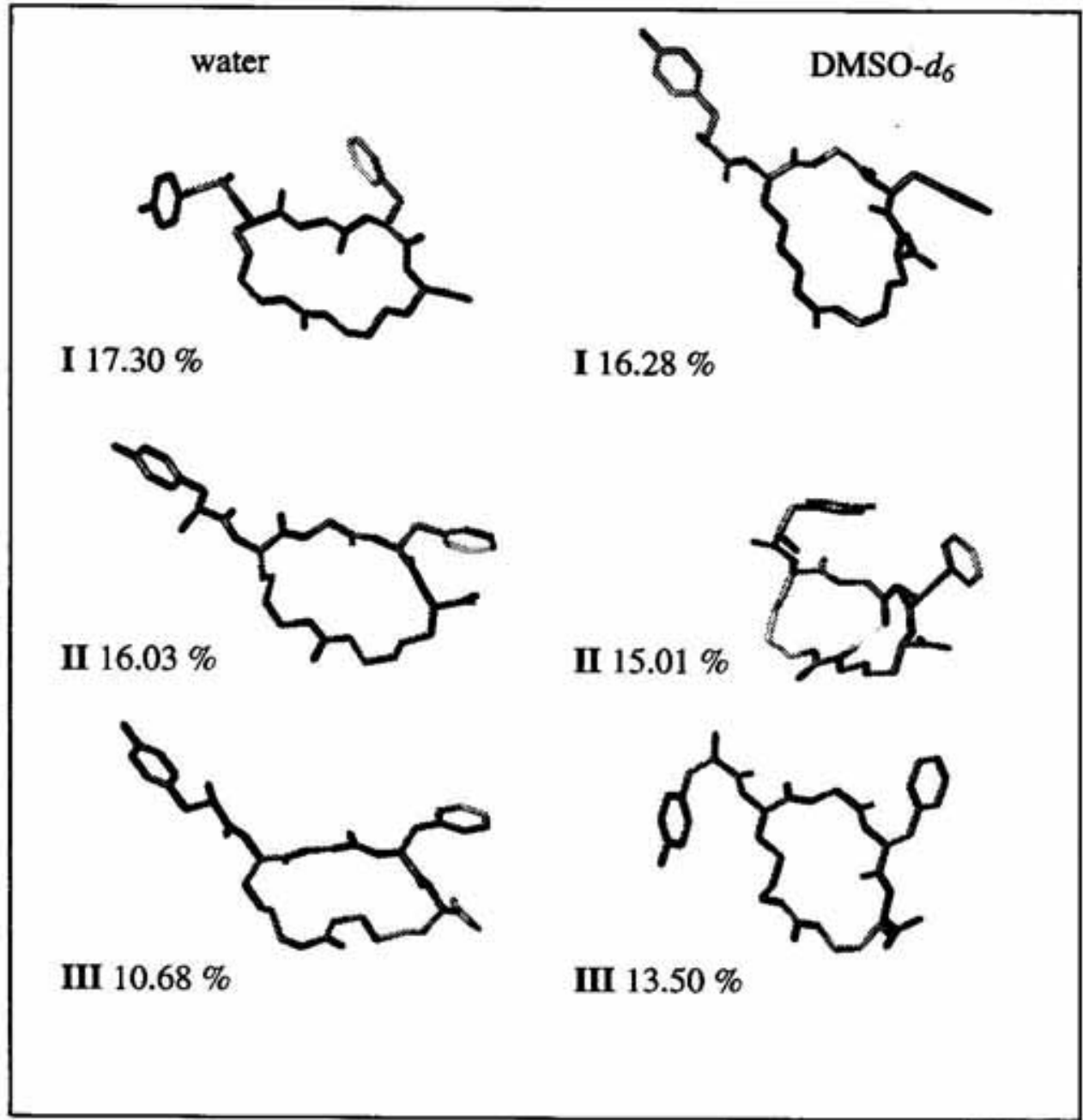

Figure 1. Three the most populated conformations of cyclo $\left(N^{f}, N^{\ell^{\prime}}\right.$-carbonyl-DLys, Lys ') '-enkephalinamide in water and $\mathrm{Me}_{2} \mathrm{SO}_{6}$.

Table 2 expressed in the Zimmerman code [34]. Conformations III and V in water and I and $\mathbf{X}$ in $\mathrm{Me}_{2} \mathrm{SO}_{-} d_{6}$ have $\mathrm{E}^{*} \mathrm{E}$ codes, IV, $\mathrm{V}$ and IX in $\mathrm{Me}_{2} \mathrm{SO}_{-} d_{6}$ have DA codes for Gly and Phe residues. In addition conformations II in water and VII in $\mathrm{Me}_{2} \mathrm{SO}_{-} d_{6}$ have $\mathrm{G}^{*} \mathrm{~B}$ codes. The three most populated conformations found in the two solvents are shown in Fig. 1.

\section{DISCUSSION}

It was found that the presence of both Phe and Tyr residues in enkephalin analogues is vital for its activity [35]. Therefore, it may be assumed that the conformation of these two residues as well as the distance between their aromatic rings is of great importance for the peptide activity. In a cyclic peptide containing the ureido bridge these may be regulated by the size of the main ring. Inspection of the data in Table 2 reveals a large diversity of conformations of the peptide chain situated between Phe and Tyr residues. Different sets of conformations were observed in the two solvents revealing the influence of the solvent type on the conformation equilibrium, however the nature of this influence is not clear yet. Our results confirm that the peptide is rather flexible in both solvents. The large conformational freedom of the peptide is clearly reflected by its relatively low selectivity towards $\delta$ and $\mu$ receptors. Therefore, we have decided to construct peptides with a smaller main ring i.e. with shorter side chains of the amino-acid residues in positions 2 and 5. This work is under way. Our studies confirm that the EDMC calculations combined with NMR data provide a useful tool for conformational studies of cyclic peptides. 
They allow to search effectively the conformational space and describe more adequately the flexibility of a peptide.

Their kind permission of Dr. H. Scheraga (Cornell University, U.S.A.) and Dr. Adam Liwo (University of Gdańsk, Poland) to use for the ECEPPAK and ANALYZE programs, respectively is acknowledged. Parameterisation of the ureido moiety by Dr. A. Liwo, Dr. W. Koźmiński's permission to use his PPJ-HMQC sequence prior to its publication are also acknowledged. M.S. and J.W. wish to thank Dr. A. Bierzyński for critical reading of the manuscript heaving revised this paper.

\section{REFERENCES}

1. Schiller, P.W., Eggimann, B., DiMaio, J., Lemieux, C. \& Nguyen, T.M.-D. (1981) Cyclic enkephalin analogs containing a cysteine bridge. Biochem. Biophys. Res. Commun. 101, 337-343.

2. Mosberg, H.I., Hurst, R., Hruby, V.J., Galligan, J.J., Burks, T.F., Gee, K. \& Yamamura, H.J. (1982) (D-Pen ${ }^{2}$, L-Cys ${ }^{5}$ )enkephalinamide D-Pen ${ }^{2}$, D-Cys ${ }^{5}$ )enkephalinamide, conformationally constrained cyclic enkephalinamide analogs with delta receptor specificity. Biochem. Biophys. Res. Commun, 106, 506512.

3. Mosberg, H.I., Hurst, R., Hruby, V.J., Gee, K., Yamamura, H.J., Galligan, J.J., Burks, T.F. (1983) Bis-penicillamine enkephalins possess highly improved specificity toward delta opioid receptors. Proc. Nath Acad. Sci. U.S.A. 80, 5871-5874.

4. DiMaio, J. \& Schiller, P.W. (1980) Acyclic enkephalin analog with high in vitro opiate activity. Proc. Natl. Acad. Sci. U.S.A. 77, $7162-7166$.

5. DiMaio, J., Nguyen, T.M.-D., Lemieux, C. \& Schiller, P.W. (1982) Synthesis and pharmacological characterization in vitro of cyclic enkephalin analogues: Effect of conformational constraints on opiate receptor selectivity. J. Med. Chem. 25, 1432-1438.

6. Schiller, P.W., Nguyen, T.M.D. \& Miller, J. (1985) Synthesis of side-chain to side-chain cyclized peptide analogs on solid supports. Int. J. Protein Res. 25, 171-177.

7. Pawlak, D., Chung, N.N., Schiller, P.W. \& Izdebski, J. (1997) Synthesis of a novel sidechain to side-chain cyclized enkephalin analogue containing a carbonyl bridge. J. Pept. Sci. 3, 277-281.

8. Aue, W.P., Bartholdi, E. \& Ernst, R.R. (1976) Two-dimensional spectroscopy. Application to nuclear magnetic resonance. J. Chem. Phys. 64, 2229-2246.

9. Bax, A. \& Freeman, R. (1985) Enhanced NMR resolution by restricting the effective sample volume. J. Magn. Reson. 65, 355-360.

10. Braunschweiler, L. \& Ernst, R.R. (1983) Coherence transfer by isotropic mixing; application to proton correlation spectroscopy. $J$. Magn. Reson. 53, 521-528.

11. Bothner-By, A.A., Stephens, R.L., Lee, J.-M., Warren, C.D. \& Jeanloz, R.W. (1984) Structure determination of a tetrasaccharide: Transient nuclear Overhauser effects in the rotating frame. J. Am. Chem. Soc. 106, 811813.

12. Bax, A. \& Davis, D.G. (1985) Practical aspects of two-dimensional transverse NOE spectroscopy. J. Magn. Reson. 63, 207-213.

13. Kay, L.E., Keifer, P. \& Saarinen, T. (1992) Pure absorption gradient enhanced heteronuclear single quantum correlation spectroscopy with improved sensitivity. J. Am. Chem. Soc. 114, 10663-10665.

14. Palmer III, A.G., Cavanagh, J., Wright, P.E. \& Rance, M. (1991) Sensitivity improvement in proton-detected two-dimensional heteronuclear correlation NMR spectroscopy. J. Magn. Reson. 93, 151-170. 
15. Kontaxis, G., Stonehouse, J., Laue, E.D. \& Keeler, J. (1994) The sensitivity of experiments which use gradient pulses for coherence-pathway selection. J. Magn. Reson. Ser. A 111, 70-76.

16. Koźmiński, W. (1999) A pure-phase homonuclear $\mathrm{j}$-modulated HMQC experiment with tilted cross-peak patterns for an accurace determination of homonuclear coupling constans. J. Magn. Reson. 140 (in press).

17. Gottlieb, H.E., Kotlyar, V. \& Nudelman, A. (1997) NMR chemical shifts of common laboratory solvents as trace impurities. J. Org. Chem. 62, 7512-7515.

18. Wishart, S., Bigam, C.G., Holm, A., Hodges, R.S. \& Sykes, B.D. $(1995){ }^{1} \mathrm{H},{ }^{13} \mathrm{C}$ and ${ }^{15} \mathrm{~N}$ random coil NMR chemical shifts of the common amino acids. I. Investigations of nearst-neighbor effects. J. Biomol. NMR 5, 67-81.

19. Hoffman, R.E. \& Davies, D.B. (1988) Temperature dependence of NMR secondary references for $\mathrm{D}_{2} \mathrm{O}$ and $\left(\mathrm{CD}_{3}\right)_{2} \mathrm{SO}$ solutions. Magn. Reson. Chem. 26, 523-525.

20.Liwo, A., Tempczyk, A., Ołdziej, S., Shenderovich, M.D., Talluri, S., Ciarkowski, J., Kasprzykowski, S., Lankiewicz, L. \& Grzonka, Z. (1996) Exploration of the conformational space of oxytocin and arginine-vasopressin using the electrostatically driven Monte Carlo and molecular dynamics methods. Biopolymers 38, 157-175.

21. Ripoll, D. \& Scheraga, H.A. (1988) On the Multiple-minima problem in the conformational analysis of polypeptides. II. An electrostatically driven Monte Carlo method - tests on poly(L-alanine). Biopolymers 27, 1283-1303.

22. Ripoll, D. \& Scheraga, H.A. (1990) On the multiple-minima problem in the conformational analysis of polypeptides. IV. Application of the electrostatically driven Monte Carlo method to the 20-residue membrane-bound portion of melittin. Biopolymers 30, 165-176.
23. Nemethy, G., Gibson, K.D., Palmer, K.A., Yoon, Ch.N., Paterlini, G., Zagari, A., Rumsey, S. \& Scheraga, H.A. (1992) Energy parameters in polypeptides. 10 . Improved geometrical parameters and nonbonded interactions for use in the ECEPP/3 algorithm, with application to proline-containing peptides. J. Phys. Chem. 96, 6472-6484.

24.Vila, J., Williams, R.I., Vasquez, M. \& Scheraga, H.A. (1991) Empirical solvation models can be used to differentiate native from near-native conformations of bovine pancreatic trypsin inhibitor. Proteins: Struct. Fun. Genet. 10, 199-218.

25.Li, Z. \& Scheraga, H.A. (1987) Monte Carlo-minimization approach to the multiple-minima problem in protein folding. Proc. Natl. Acad. Sci. U.S.A. 84, 6611-6615.

26.Piela, L. \& Scheraga, H.A. (1987) On the multiple-minima problem in the conformational analysis of polypeptides. I. Backbone degrees of freedom for a perturbed $\alpha$-helix. Biopoly mers 26, S33-S58.

27. Metropolis, N.S., Rosenbluth, A.W., Rosenbluth, M.N., Teller, A.H. \& Teller, E. (1953) Equation of state calculations by fast computing machines. J. Chem. Phys. 21, 1087-1092.

28. Spath, H. (1980) Cluster Analysis Algorithms pp. 170-194, Halsted Press, New York.

29. Meadows, R.P., Post, C.B., Luxon, B.A. \& Gorenstein, D.G. (1994) MORASS 2.1, W. Lafayette, Purdue University.

30.Post, C.B., Meadows, R.P. \& Gorenstein, D.G. (1990) On the evaluation of interproton distances for three-dimensional structure by NMR using a relaxation rate matrix analysis. J. Am. Chem. Soc. 112, 6796-6803.

31. Marquardt, D.W. (1963) An algorithm for least-squares estimation of nonlinear parameters. J. Soc. Indust. Appl. Math. 11, 431-441. 
32. Croasmun, W.R. \& Carlson, R.M.K. (1994) Two-Dimensional NMR Spectroscopy (2nd edn.) p.329, VCH Publishers, Inc. New York.

33. Coles, M., Sowemimo, V., Scanlon, D., Munro, S.L.A. \& Craik, D.J. (1993) A conformational study by ${ }^{1} \mathrm{H}$ NMR of a cyclic pentapeptide antagonist of endothelin. J. Med. Chem. 36, 2658-2665.
34.Zimmerman, S.S., Pottle, M.S., Nemethy, G. \& Scheraga, H.A. (1976) Conformational analysis of the 20 naturally occuring amino acid residues using ECEPP. Macromolecules 10, 1-9.

35. Schiller, P.W. (1987) Peptides (Underfriends, S. \& Meienhofer, J., eds.) 8, 257-263, Orlando Academic Press. 